\title{
Distributivity and Genericity in Greek: The Case of kathe with the Definite Article
}

\author{
Dimitra Lazaridou-Chatzigoga \\ University of Crete \& Queen Mary, University of London \\ dimitrala_cha@yahoo.gr, d.lazaridou@qmul.ac.uk
}

\section{Abstract}

This paper discusses the co-occurrence of the universal distributive quantifier kathe with the definite article $(0, i$, to $)$ in Greek. Following Beghelli \& Stowell (1997) and Tunstall (1998) I argue that while both bare kathe-phrases and kathephrases with the definite article (henceforth o kathe-phrases) exhibit strong distributivity, o kathe-phrases are linked to obligatory and total distribution, while bare kathe-phrases are linked to optional and partial distribution. As far as genericity is concerned, kathe can be generic, while o kathe cannot, because it is presuppositional. The contribution of the definite article in this construction is associated with weak familiarity and the count-as-unique condition.

\section{Introduction ${ }^{1}$}

This paper concerns the interaction between determiners and quantifiers in the Greek N(oun) P(hrase), as evidenced in the construction [definite article $\left(0, i, t_{0}\right)+$ kathe 'every/each' + Noun], focusing on two semantic properties, distributivity and genericity. Here is an example:

\footnotetext{
1 I would like to thank especially Louise McNally, as well as Elena Anagnostopoulou, Josep M. Brucart, M. Teresa Espinal, Winfried Lechner, Josep Quer, Melita Stavrou, Evangelia Vlachou, the people at the Athens reading group in Linguistics and the two anonymous reviewers, who all helped me with insightful comments and suggestions. Needless to say that any remaining errors are mine. This paper draws on my PhD thesis (LazaridouChatzigoga 2009b), completed amb el suport del Comissionat per a Universitats $i$ Recerca del Departament d'Innovació, Universitats i Empresa de la Generalitat de Catalunya.
}

\section{(cc) BY-NC-ND}


(1) O kathe fotoghrafos tha feri pendefotoghrafiesapo tin siloghi tu. the kathe photographer fut bring.3sg five photographs from the collection his 'Each photographer will bring five photographs from his collection.'

It is not uncommon to encounter the definite article co-occurring with other determiners in Greek, as is evident, for instance, in demonstratives, possessives and with the universal quantifier olos 'all' (see among others MarmaridouProtopapa 1984, Lyons 1999, Alexiadou et. al 2007 and Giannoulopoulou 2007). A striking difference of the construction in question is the fact that this co-occurrence seems redundant ${ }^{2}$, since the universal distributive quantifier kathe is an item that can also form an NP combining with a Noun with no other determiner present. This does not hold either for demonstratives or for possessives.

\section{Morphological, Syntactic and Semantic Characteristics of (o) kathe}

\subsection{Morphological and Syntactic Characteristics}

In this paper I focus on the semantic characteristics of (o) kathe, but let me just briefly point out the main morphological and syntactic characteristics of (o) kathe: a) kathe is not inflected, b) (o) kathe does not occur without a Noun, and c) (o) kathe is always preceding the Noun:

(2) (To) kathe pedhi pire ena dhoro. the kathe child got.3sg a present 'Every ${ }^{3}$ child got a present.'

(3) *(To) kathe pire ena dhoro. the kathe got.3sg a present

(4) "Pedhi (to) kathe pire ena dhoro. child the kathe got.3sg a present

2 For another co-occurrence of the definite article with a determiner, namely, the cooccurrence with opjosdhipote 'FC any' see Lazaridou-Chatzigoga (2007, 2009a,b). For the construction in question through a cross-linguistic point of view, see Etxeberria \& Giannakidou (2008) for Basque and Matthewson (2001) for Lilloet Salish. This aspect of the phenomenon remains for future research.

3 For expository reasons, I translate here (o) kathe with every, but as will be obvious in the discussion, kathe is to be translated as every, while o kathe as each. 
From (4) we can deduce that (o) kathe is not a floating quantifier, that is, its syntactic position is fixed. In contrast, other universal quantifiers like olos, can float, as they can appear in various positions within a sentence, as seen below:

(5) Olata pedhia mpikan stin taksi/Ta pedhia mpikanolastin taksi. all the children entered in.the class/ the children entered all in.the class 'All the children entered the class/ The children all entered the class.'

\subsection{Semantic Characteristics}

Before entering into the discussion of distributivity and genericity with respect to (o) kathe, let me highlight two distinctive semantic properties of this quantifier. The first one has to do with the scope properties of (o) kathe. (0) kathe has the tendency to receive wide scope with respect to other quantifiers, a fact in accordance with observations regarding similar quantifiers in other languages ${ }^{4}$. In sentences like the following, which are scopally ambiguous, the first reading is the preferred one, according to which kathe musikos 'every musician' scopes over the indefinite mia klimaka 'a scale':

(6) (0) kathe musikos kseri mia klimaka.

the kathe musician knows a scale

'Every musician knows a scale.'

$6^{\prime} \forall x(\operatorname{musician}(x) \rightarrow \exists y($ scale $(y) \wedge$ know $(x, y)))$

$6^{\prime \prime} \exists y($ scale $(y) \wedge \forall x($ musician $(x) \rightarrow$ know $(x, y)))$

The second distinctive property is that kathe can quantify over atomic individuals, as we saw above in (2), or plural individuals in the sense of Link (1983), as we see below. Kathe here quantifies over the plural individual formed by tris katikus 'three citizens', which serves as the minimum unit kathe quantifies over. This is though not possible for o kathe, as we see below:

(7) Iposhethikan na fitepsun ena dentro ya kathe tris katikus/"tus kathe tris katikus. promised.3pl subj plant a tree for kathe three citizens/the kathe three citizens 'They promised to plant a tree for every three citizens.'

The quantification here is only possible over groups of three, which means that we have no access to the sub-parts of the plural individual, a fact that is

4 See loup (1975) for a Quantifier Hierarchy regarding scope: each > every > all > most > many $>$ several $>$ some $_{p l}>$ a few. 
predicted under my analysis, which presupposes access to each and every entity in the kathe-set.

\section{3. (O) kathe: Distributivity and Genericity}

In the descriptive literature only the emphatic nature of the construction is pointed out (Holton, Mackridge \& Philippaki-Warburton 1999: 311), and no clear explanation is given to the apparent optionality of the co-occurrence of the definite article with kathe. Building though on previous analyses (Giannakidou 1999, 2004, Tsili 2001, Exteberria \& Giannakidou 2008) I will refine the semantic characteristics of $o$ kathe drawing on distributivity and genericity. Before entering into the discussion, let me illustrate the phenomenon with more examples ${ }^{5}$ :

(8) Videoskopuse to kathe vima tis. filmed.3sg-IMPFVE the kathe step her 'She filmed each and every step of hers.'

(9) I Inofotoghrafise to kathe zoo tu zoologhikukipu. the Ino photographed.3sg the kathe animal the-GEN zoologic garden 'Ino photographed each animal of the zoo.'

(10) Kathe hrono ipologhizete oti 5 ekatomiria theates vlepun, kata meson oro, tis 1200 parastasis tu 'holiday on ice', pu dinonte se 70 polis apo 15 hores [...] I kathe parastasi periodevi ya tria hronia.

'Every year it is calculated that 5 millions spectators watch, on average, the 1200 performances of 'Holiday on Ice' that are given in 70 cities in 15 countries [...] Each performance is on tour for two years.'

The discussion illustrates the two main points of this paper: a) the fact that bare kathe-phrases and $o$ kathe-phrases are not interchangeable in all contexts and b) the issue of the contribution of the definite article in this construction. In order to address the first issue I will be concerned with the properties of distributivity and genericity in subsections 3.1 and 3.2, respectively. In order to answer the second issue, I will discuss the notion of definiteness in section 4.

$\mathbf{5}$ I have left outside the scope of my paper occurrences of o kathe N, which I think deserve a different treatment, being similar to minimizers and pointing to the end of a scale: Ehume varethi ton kathe asheto stis tileorasis 'lit. we are bored of the kathe ignorant on the TV'. On these occurrences see Margariti (2007). 


\section{1. (0) kathe and Distributivity}

In the literature we encounter two main refinements of distributivity, one proposed by Beghelli \& Stowell (1997; B\&S henceforth) and the other proposed by Tunstall (1998). B\&S (1997) discuss distributivity with respect to all, every and each and propose two differentiations. The first concerns the difference between strong distributivity, attested in NPs with every and each, and pseudo-distributivity/ weak distributivity, attested in NPs with all. This type of distributivity depends on whether the NP can have a collective interpretation or not. (O) kathe is not compatible with collective predicates (Dowty 1987) like mazevome 'gather' in contrast to olos 'all', so (o) kathe is related to strong distributivity, while olos to pseudodistributivity.

(11) Ola ta pedhia mazeftikan stin avli. all the children gathered in.the yard 'All the children gathered in the yard.'

(12) *(To) kathe pedhi mazeftike stin avli. the kathe child gathered in.the yard

A further subdivision concerns what BES (1997) call optional distributivity, as with every, and obligatory distributivity, as with each. As far as Greek is concerned, I follow Tsili (2001), who argues that kathe is optionally distributive, while 0 kathe obligatorily distributive. The application of the tests that B\&S (1997) use for every/ each to the Greek items highlights the parallel distribution between every and kathe and each and o kathe-phrases:

a. O kathe-phrases cannot appear in universal collective readings:

*Katevalan tin kathe prospathia ya na lithi to thema. ${ }^{6}$ they.strained the kathe intent to solve the issue

b. O kathe-phrases cannot be modified by shedhon 'almost', in contrast to kathe-phrases:

(14) Mia musikos mantepse sosta shedhon \{kathe traghudhi/ "to kathe traghudhi\}. a musician guessed.3sg correctly almost kathe song/ the kathe song

6 As an anonymous reviewer points out this might be due to a more general phenomenon concerning periphrases like katavalo prospathia 'lit. strain intent'or simiono proodho 'lit. mark progress', which are hostile to the occurrence of the definite article. 
c. There are constructions similar to floating and binominal each, expressed via o kathenas 'lit. the eachone', which crucially involve the definite article:

(15) Ta pedhia efaghan dhio mila to kathena. the children ate.3pl two apples the each.one 'The kids ate two apples each.'

Despite the construction above, a noted difference concerns the fact that (o) kathe cannot float, in contrast to each. For this reason, we cannot adopt accounts that have been offered for the co-occurrence of other universal quantifiers with the definite article that appeal to the floating nature of quantifiers like all. Such an account has been put forward by Brisson (1998), who argues that all is not quantificational, but rather a kind of exhaustivity marker.

A second refinement of distributivity proves to be crucial for (o) kathe. Tunstall (1998) discusses distributivity and claims that every and each require multiple, or distributive, event structures, where the members of their restrictor set are associated with a number of different subevents ${ }^{7}$. In the case of every she argues that there is a condition that the event must be at least partially distributive and in the case of each there is a condition that the event must be totally distributive. Turning to example (9), repeated here, we see how the above distinction is applied to the event structures associated to the following nominals:

(16) I Ino fotoghrafise [kathe/to kathe] zoo tu zoologhiku kipu. 'Ino photographed kathel the kathe animal of the zoo.'

For (16), the scenario (a) below is ruled out, because we cannot have a collective interpretation with (o) kathe $e^{8}$. The event of taking photos of all the

7 The conditions for every and each (Tunstall 1998: 99 and 100 respectively) are defined as follows:

1. The Event Distributivity Condition

A sentence containing a quantified phrase headed by every can only be true of event structures which are at least partially distributive. At least two different subsets of the restrictor set of the quantified phrase must be associated with correspondingly different subevents, in which the predicate applies to that subset of objects.

2. The Differentiation Condition

A sentence containing a quantified phrase headed by each can only be true of event structures which are totally distributive. Each individual object in the restrictor set of the quantified phrase must be associated with its own subevent, in which the predicate applies in that object, and which can be differentiated in some way from the other subevents.

8 An anonymous reviewer points out that the scenario (a) is not ruled out for kathe, This would be though a scenario expressed in Greek with the universal quantifier olos,-i,-o 'all', which receives a collective interpretation. 
animals in the zoo has to be partially differentiated with kathe, while totally differentiated with o kathe. In the version with kathe, (16) can be claimed to be true in a setting where Ino took four photos in a real small zoo, with a total of five animals, and say, for instance, the giraffe and the hippo were photographed together, while the remaining three animals, the zebra, the monkey and the fox were each photographed separately (scenario c below). This cannot be a possible scenario for o kathe, since each animal must be associated with each individuated event of photo-taking. The partially distributive scenarios (b) and (c) are ok for kathe, but are ruled out for 0 kathe-phrases, for which only the (d) scenario of complete/total distribution is legitimate:

a. zebra

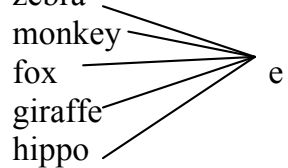

COLLECTIVE

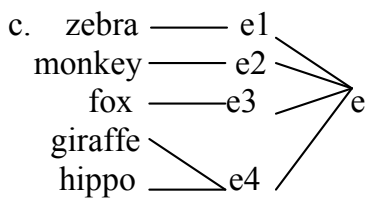

PARTIAL DISTRIBUTION

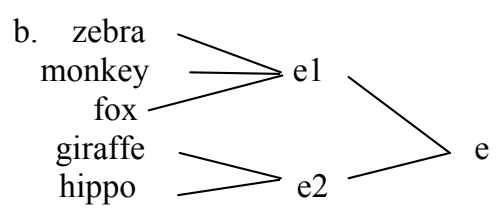

PARTIAL DISTRIBUTION

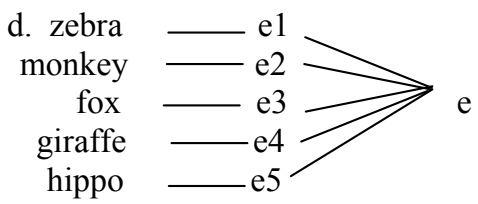

TOTAL DISTRIBUTION

I argue that the difference between kathe and o kathe is that whereas kathe requires that there be at least two distinct subevents (for every object that is acted upon in one subevent we simply need to find one other object that is acted upon in another subevent), o kathe requires all the subevents to be distinct (for every affected object we must check that all other objects are in another subevent). This fact, found implicit in Giannakidou's account (2004), is made clear if we add ala ohi ksehorista 'but not separately'. This modification marks that the subevents are not totally distributed to each and every animal in the zoo, and is thus deviant when we have o kathe:

(17) I Inofotoghrafise to kathe zoo tu zoologhikukipu, the Ino photographed the kathe animal the-GEN zoologic garden, \# ala ohi ksehorista.

but not separately

'Ino photographed each animal of the zoo, \# but not separately.' 
Support for this claim concerning every and each comes from an observation made by Vendler (1967:78), who argued that "[There is] a marked difference in emphasis: every stresses completeness or, rather, exhaustiveness...; each on the other hand, directs one's attention to the individuals as they appear, in some succession or other, one by one. Such an individual attention is not required in vain: you have to do something with each of them, one after the other". What I claim here (to be discussed in detail in section 4) is that what you have to do with each of the individuals in question is apply the count-as-unique condition to each and every one them, one after the other. Furthermore, that this condition is associated to the definite article in Greek, while in other languages, such as English, this process may be lexicalized.

\section{2. (0) kathe and Genericity}

If we now turn to genericity, we observe that the distribution of every and each (Gil 1992; BES 1997) is parallel to the distribution of kathe and o kathe. Giannakidou $(1999,2004)$ has argued that kathe can be generic, while o kathe cannot9, and the following examples (adaptions from Gil 1992) corroborate this claim, with the importance of discourse being underlined:

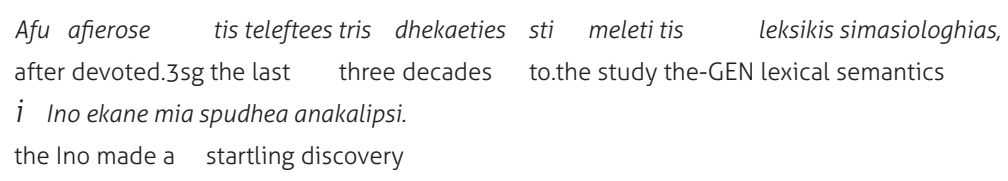

9 This generalization is initially surprising, because genericity in Greek is typically expressed with definite noun phrases, mostly plurals, like i falenes ine thilastika 'lit. the whales are mammals', but also singulars as in $i$ fanela ine thilastiko 'lit. the whale is a mammal'. Due to space, we cannot elaborate more on this point, but we think that the fact that (o) kathe is necessarily singular might be one crucial parameter. 
d.I ghloses ehun panoapoikosi leksis ya hromata. the languages have over twenty words for colours

'Languages have over twenty words for colours.'

(19) I Ino molis anakalipse dheka aghnostes mehri tora ghloses sta ipsipeda the Ino just discovered ten unknown hitherto languages in.the highlands tis Papua sti Nea Guinea.

the.gen Papua in.the New Guinea

'Ino has just discovered ten hitherto unknown languages in the Papua highlands in New Guinea.'

a. ?Kathe ghlosa ehi panoapo ikosi leksis ya hromata. kathe language has over twenty words for colours

b.?Olesi ghloses ehun panoapoikosi leksis yahromata. all the languages have.3pl over twenty words for colours

c.l kathe ghlosa ehi pano apo ikosi leksis ya hromata. the kathe language has over twenty words for colours 'Each language has over twenty words for colours.'

d. ?I ghloses ehun pano apoikosi leksis ya hromata. the languages have over twenty words for colours

In (18) we have a context, according to which Ino studies lexical semantics and makes a discovery about the color terms languages use to have. Since no explicit mention of languages is made in the context, Ino's discovery can be presented with a generic NP headed by kathe, oles 'all' or a definite plural (the usual way to express genericity in NPs in Greek), but crucially not with o kathe. Moving now to a context, where Ino has discovered ten previously unknown languages and then studies the color terms they have, we see that the situation in (19) is reversed: kathe, oles 'all' and the definite plural are deviant, while $o$ kathe is completely grammatical, referring to each and every one of the ten languages discovered by Ino.

I argue that additional support for the non-genericity of o kathe comes from the following type of contexts: a) individual-level predicates, b) there-insertion contexts and c) intensional contexts.

First, (o) kathe-phrases can appear with individual-level predicates (Carlson 1977), that is, predicates that express permanent properties of individuals, as below:

(20) Kathe ghata ehi tesera podhia/ I kathe ghata ehi tesera podhia.

'Every cat has four legs / Each cat has four legs.'

Both sentences are grammatical, but the claim with the definite article can only be true of some particular set of cats previously introduced in the discourse 
and cannot be generic. When reference is made to kinds, of which there are no instances in the actual world, we observe that o kathe becomes unacceptable. This is due to the fact that kathe can make claims both about the actual and possible worlds, while o kathe can only refer to the actual world, and more restrictively to the universe of discourse, as argued by Etxeberria \& Giannakidou (2008), from whom I quote the following example:

(21) Kathe monokeros ehi ena kerato/ \#O kathe monokeros ehi ena kerato. 'Every unicorn has one horn.'/' Each unicorn has one horn.'

Following Etxeberria \& Giannakidou, I claim that when we have o kathe the claim can only be made about a specific set of unicorns, e.g. only if we imagine an illustration in a book that is present physically at the time of conversation, since $o$ kathe cannot escape reference to the universe of discourse. To account for the intuition, I follow Kratzer's (1981) theory on modality and claim that 0 kathe-phrases seem to be associated with a realistic modal base.

Second, there-insertion contexts, which in general disallow strong quantifiers (Milsark 1974) like every or kathe, may favor a kind interpretation under certain conditions (McNally \& Van Geenhoven 1998). In this type of contexts, kathe is licensed, while $o$ kathe is ungrammatical:

(22) Sto dhiadhiktio iparhi kathe/"i kathe idhous pliroforia ya tin evrizonikotita. in.the internet exists kathe/ the kathe kind.GEN information for the.ACC broadband 'In internet, there is every kind of information on broadband.'

Third, kathe-phrases with intensional verbs like psahno 'look for' give rise both to opaque and transparent readings, while o kathe-phrases only to transparent ones:

(23) Epsaksa na vro kathe lathos sto hiroghrafo (ala den ipirhe kanena)/ to kathe lathos sto hirografo (\#ala den ipirhe kanena).

'I looked for kathe/ the kathe error in the manuscript (but there wasn't any)'

On the basis of the above observations, I argue that $o$ kathe is presuppositional (Heim \& Kratzer 1998), that is, it presupposes a non-empty domain, while kathe makes no claim with respect to its domain, it may be empty or not. Giannakidou (2004) also underlines the presuppositionality of o kathe casting it into an account of veridicality on the basis of its behaviour with respect to negative polarity items, which can appear in the argument of the NP of kathe, but not of 0 kathe, as the following example from Giannakidou (1999: 396) shows: 
(24) a. Kathefititis pu ghnorizi tipota shetikame tin ipothesi, as milisi tora. every student that know.3sg anything about with the case subj talk.3sg now 'Every student who knows anything about the case should speak now.'

b. "O kathe fititis pu ghnorizi tipota shetika me tin ipothesi, as milisi tora the every student that know.3sg anything about with the case subj. talk.3sg now

\section{The Proposal: the Semantics of the Definite Article with kathe}

In the light of the above distribution of o kathe-phrases with respect to distributivity and genericity, it should be clear by now that the definite article does have a contribution when appearing with kathe. Kathe-and o kathe-phrases are not interchangeable in all contexts, given that a) o kathe requires obligatory distribution and b) o kathe cannot be generic. In this section I will focus on my proposal of the nature of this contribution.

A first piece of evidence when addressing this issue is the fact that the construction [definite article + kathe + Noun] does not seem to build a definite NP (Giannakidou 2004) on the basis of the following strong evidence: The definite article appearing here cannot spread, so it cannot give rise to determiner spreading or polydefiniteness (see Alexiadou and Wilder 1998, Kolliakou 2004 and Campos \& Stavrou 2005 among others):

(25) To kathe pedhi tha pari mia karamela.

the kathe child fut get a candy

'Each child will get a candy.'

(26) "To kathe to pedhi tha pari mia karamela. the kathe the child fut get a candy

(27) *To kathe to mikro to pedhi tha pari mia karamela. the kathe the small the child fut get a candy

The definite article co-occurring with kathe does nevertheless have a semantic repercussion in the interpretation of the nominal. On the basis of the construction in question and the co-occurrence of the definite article with the Free Choice Item opjosdhipote 'FC any' in Greek, in Lazaridou-Chatzigoga (2009b) I proposed a reconsideration of the notion of definiteness. My proposal was based on (weak) familiarity, as in Roberts (2003), and on a redefinition of the notion of uniqueness as the count-as-unique condition, inspired by the ontological insights of the philosophical work of Badiou (1988). Here is the definition I advanced: 
(28) Definition of definite

Given a context $C$, use of a definite $N P_{i}$ presupposes that it has as antecedent discourse referent $x_{i}$, which is:

a) weakly familiar in C (Roberts 2003) and

b) counted-as-unique among discourse referents in $\mathrm{C}$ in being contextually entailed to satisfy the descriptive content of $\mathrm{NP}_{\mathrm{i}}$

I argue that the contribution of the definite article in o kathe-phrases amounts to the two conditions of definiteness as defined above. (Weak) familiarity is satisfied in o kathe-phrases, as can be seen in examples (10) and (19) above ${ }^{10}$. The Count-as-unique (count-U) condition is formalized as follows:

(29) The count- $U$ condition

$[\forall x: P(x)][$ count $-U(x)]$

to be read: for every $x$ that has the property $P, x$ is counted-as-unique

Under the count- $U$ condition I envisage an operation that takes place whenever the definite article is used in such a construction. This part of the meaning of the definite article is like a presupposition, and could be seen as part of the procedural meaning in the context of recent advances in Relevance Theory (Wilson and Sperber 2012). In o kathe the procedure is as follows: The speaker makes a plea for the hearer to make sure that she fully distributes the counting to each and every one of the members of the kathe-set. The property in question is already interpreted in a distributive way, but the definite article adds to this that the distribution may not be partial, but it needs to be total. Each member of the kathe-set is counted-as-unique, in the sense that it is given its own separate event structure, which may not overlap with the one or the other member of the set.

Following the received view on quantifiers in natural language (Barwise \& Cooper 1981), kathe denotes a generalized quantifier:

(30) $[[k a t h e]]=\lambda P \lambda \mathrm{O}[\forall x: \mathrm{P}(x)][\mathrm{O}(\mathrm{x})]$

If we apply the above formalization to (9), repeated here for convenience, we end up with the following semantic representation for the o kathe-phrase:

(31) I Ino fotoghrafise to kathe zoo tu zoologhiku kipu.

'Ino photographed each animal of the zoo.'

10 A more detailed account of how o kathe satisfies (weak) familiarity is beyond the scope of this paper, but it is part of ongoing research with corpora. The focus here is on the count- $U$ condition, given that this is the part of the meaning that formalizes the most significant differences between kathe and $o$ kathe. 
(32) $[[$ kathe zoo $]]=\lambda \mathrm{O}[[\forall x$ : animal $(x)][Q(x)]$ and the definite article adds the count- $U$ condition: $[\forall x$ : animal $(x)]$ [count- $U(x)]$

The proposal advanced here emphasizes the counting process of each and every entity involved, representing the total distribution and the non-generic nature of the construction. The Count- $U$ condition predicts that we need to have access to the instances, to the individuals one by one, so no reference to the kind is possible when the definite article is present. And this is indeed what we found in the section discussing the non-genericity of o kathe. I associate the contribution of the definite article in o kathe with the regular meaning of the definite article, contrasting in this with an analysis that treats the definite article as an overt domain restrictor and claims that $o$ kathe is a complex quantifier (see Giannakidou 2004), essentially giving to the Greek definite article an added meaning.

\section{Conclusions}

In this paper I have argued that the construction [definite article + kathe + Noun] is related to strong and obligatory distribution in the sense of Beghelli \& Stowell (1997) and that it requires total distribution in the sense of Tunstall (1998). Furthermore, o kathe cannot refer to a kind, thus it cannot be generic, and it is presuppositional (Heim \& Kratzer 1998). The contribution of the definite article in this construction amounts to the two conditions of definiteness, weak familiarity and the Count- $U$ condition, as defined in Lazaridou-Chatzigoga (2009b). 


\section{References}

Alexiadou, A., L. Haegeman and M. Stavrou. 2007. Noun phrase in the generative perspective. Berlin: Mouton de Gruyter.

Alexiadou, A. and C. Wilder 1998. Adjectival modification and multiple determiners. In Alexiadou, A. and C. Wilder (eds.), Possessors, predicates and movement in the DP, Amsterdam. 303-332.

Badiou, A. 1988. L'Etre et l'événement. English translation: Being and event. Trans. O. Feltham. London, Continuum, 2005.

Barwise, J. and R. Cooper. 1981. Generalized quantifiers in natural language. Linguistics and Philosophy 4(1): 159-219.

Beghelli, P. and T. Stowell. 1997. Distributivity and Negation. In A. Szabolcsi (ed.), Ways of Scope Taking. Dordrecht: Kluwer.

Brisson, C. 1998. Distributivity, Maximality, and Floating Quantifiers. PhD Dissertation, Rutgers University.

Campos, H. and M. Stavrou 2004. Polydefinite constructions in Modern Greek and in Aromanian. In Tomic (ed.), Balkan Syntax and Semantics, John Benjamins. 137-144.

Carlson, G. 1977. Reference to kinds. New York: Garland. PhD thesis, UMass, Amherst.

Dowty, D. 1987. Collective Predicates, Distributive Predicates, and All. In F. Marshall et al. (eds.), ESCOL '86: Proceedings of the Third Eastern States Conference on Linguistics. Columbus: Ohio State University.

Etxeberria, U. and A. Giannakidou. 2008. Contextual domain restriction across languages: Definiteness, indefiniteness and the structure of $\mathrm{QP}, \mathrm{ms}$. 
Giannakidou, A. 1999. Affective dependencies. Linguistics and Philosophy 22: 367-421.

Giannakidou, A. 2004. Domain restriction and the arguments of quantificational determiners. In Semantics and Linguistic Theory 14. Cornell Linguistics Club: Ithaca, NY. 110-128.

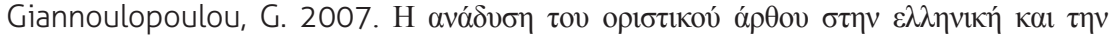

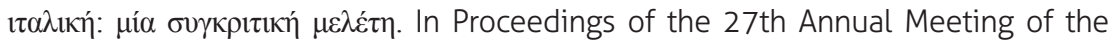
Department of Linguistics. Thessaloniki, Aristotle University of Thessaloniki. 78-89.

Gil, D. 1992. Scopal quantifiers: Some universals of lexical effability. In M. Kefer and J. van der Auwera (eds.), Meaning and grammar cross-linguistic perspectives, 303-345.

Heim, I. and A. Kratzer. 1998. Semantics in generative grammar. Malden, MA: Blackwell Publishers.

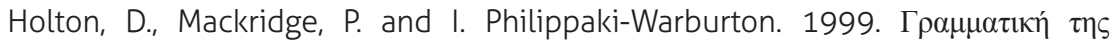
$\varepsilon \lambda \lambda \eta v i \kappa n ́ s ~ \gamma \lambda \omega ́ \sigma \sigma \alpha \varsigma$. Athina: Patakis.

loup, G. 1975. The Treatment of Quantifier Scope in a Transformational Grammar. PhD Dissertation, The City University of New York, NY.

Kolliakou, D. 2004. Monadic definites and polydefinites: their form, meaning, and use. Journal of Linguistics 40: 263-333.

Kratzer, A. 1981. The Notional Category of Modality. In H.J. Eikmeyer, and H. Rieser (eds.), Words, Worlds, and Contexts. Berlin, 38-74.

Lazaridou-Chatzigoga, D. 2007. Free Choice Items and definiteness: Evidence from Greek. In E. Puig-Waldmueller (ed.), Proceedings of Sinn und Bedeutung 11. Barcelona: Universitat Pompeu Fabra, 403-417.

Lazaridou-Chatzigoga, D. 2009a. Greek Generic Noun Phrases Involving the Free Choice Item opjosdhipote and the Definite Article, Proceedings of the 2007 Workshop in Greek Syntax and Semantics at MIT, MITWPL 57 (MIT Working Papers in Linguistics), 123-137.

Lazaridou-Chatzigoga, D. 2009b. On definiteness and the co-occurrence of the definite article with other determiners in Modern Greek. Unpublished PhD thesis. Universitat Autònoma de Barcelona. 
Link, G. 1983. The logical analysis of plurals and mass terms: A lattice-theoretical approach. In R. Bauerle, C. Schwartze and A. von Stechow (eds.), Meaning, Use and Interpretation of Language. De Gruyter, 302-323.

Lyons C. 1999. Definiteness. Cambridge University Press.

Margariti, A.M. 2007. Quantification and intonation in Modern Greek. In E. Agathopoulou, M. Dimitrakopoulou and D. Papadopoulou (eds.), Selected Papers on theoretical and applied linguistics. Department of Theoretical and Applied Linguistics, School of English, Aristotle University of Thessaloniki, v.l.

Marmaridou-Protopapa, A.S.S. 1984. The study of reference, attribution and genericness in the context of English and their grammaticalization in M. Greek noun phrases. Unpublished PhD thesis. Darwin College. Cambridge.

Matthewson, L. 2001. Quantification and the nature of crosslinguistic variation. Natural Language Semantics 9: 145-189.

McNally, L. and V. Van Geenhoven. 1998. Redefining the weak/strong distinction. Paper presented at CSSP 3, Paris. ms, Universitat Pompeu Fabra and Radboud University.

Milsark, G. 1974. Existential Sentences in English. PhD thesis. MIT.

Roberts, C. 2003. Uniqueness in definite noun phrases, Linguistics and Philosophy 26, 287-350.

Tsamadou-Jacoberger, I. 2002. Le nom en grec moderne: marqueurs et opérations de détermination. Editions L'Harmattan.

Tsili, M. 2001. The quantificational phrases (o) kathe NP, (o) kathenas > universality and distributivity (In Greek). Studies in Greek Linguistics 21, 783-794.

Tunstall, S. 1998. The Interpretation of Quantifiers: Semantics and Processing. PhD thesis. UMass.

Vendler, Z. 1967. Linguistics in Philosophy. Ithaca, NY: Cornell University Press.

Wilson, D. and D. Sperber. 2012. Meaning and Relevance. Cambridge: Cambridge University Press. 